\title{
Honoring Dr Ernesto Schiffrin with the 2021 ISH Volhard Award
}

\author{
JOHN E. HALL ${ }^{1}$, ROBERT M. \\ CAREY ${ }^{1}$, TOSHIRO FUJITA ${ }^{2}$ \\ 'University of Mississippi Medical Center, \\ Mississippi, USA. \\ 2University of Tokyo, \\ Tokyo Japan.
}

DOI:10.30824/2106-10
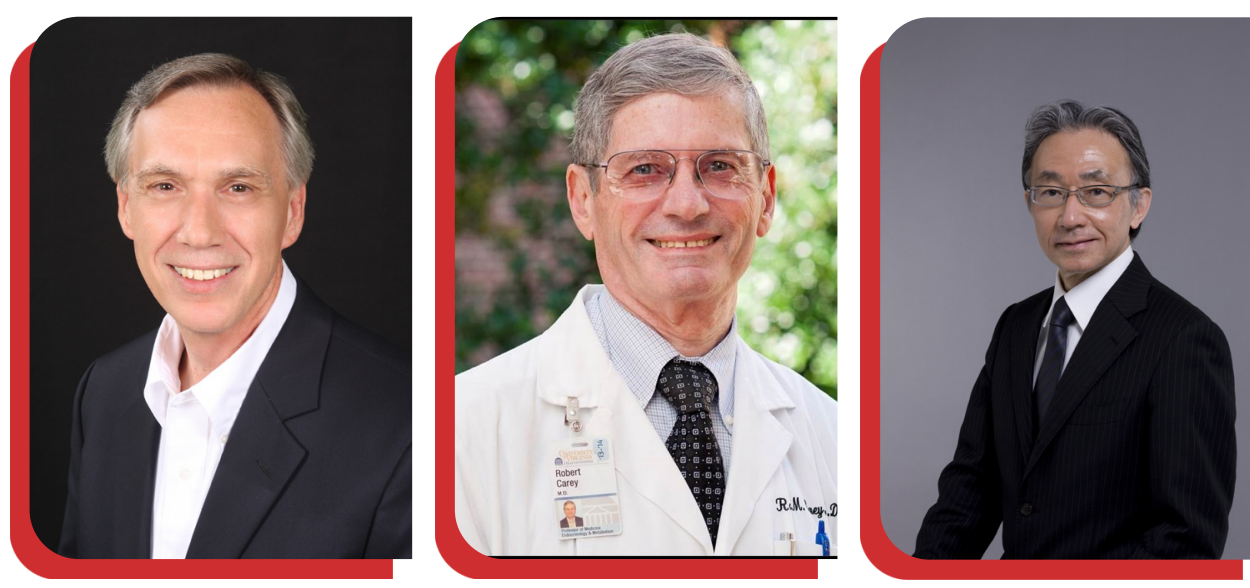

Dear Members of the International Society of Hypertension,

We extend our heartiest congratulations to Dr. Ernesto L. Schiffrin, the recipient of the 2021 Franz Volhard Award and Lectureship for Outstanding Research of the International Society of Hypertension (ISH). Ernesto is a world leader in hypertension research, cardiovascular medicine, and vascular biology. He is also a role model for young clinician scientists, combining cutting-edge research, clinical service, extraordinary leadership in international scientific organizations as well as his home institution, and mentoring many young scientists who have developed their own outstanding research programs.

Ernesto's pioneering research contributions are too numerous to discuss in detail but a few deserve special attention:

$\odot$ Discovery of the mechanisms of remodeling of small resistance arteries and the effects of antihypertensive therapy on vascular remodeling in humans, demonstrating that selective antihypertensive agents correct altered structure and function of blood vessels in patients with hypertension'.

$\odot$ Demonstration of the role of endothelin in vascular disease and in salt-sensitive and severe hypertension, leading to studies of endothelin antagonists in human resistant hypertension².

$\odot$ Discovery of the role of atrial natriuretic peptide in regulating aldosterone secretion. $\odot$ First report on the role of natriuretic peptides as biomarkers of heart failure in humans.

$\odot$ Demonstration that angiotensin II and aldosterone have important effects on cardiovascular remodeling and elucidation of the mechanisms by which these two hormones interact to cause cardiovascular injury.

$\odot$ Elucidation of the vascular protective actions of PPARs.

$\odot$ Exposition of the role of innate immunity, inflammation and T regulatory lymphocytes in vascular remodeling in hypertension ${ }^{3-5}$.

\section{$\odot$ Discovery that combinations of the an- giotensin receptor blocker, valsartan, and a neprilysin inhibitor, sacubitril, caused remarkable blood pressure lowering, and vascular and cardiac benefit in sponta- neously hypertensive rats. This work facil- itated development of Entresto $®$, now an important agent for treating heart failure.}

These achievements, and many more, demonstrate the broad scope of Ernesto's contributions to basic and clinical research and underscore his research leadership in hypertension and cardiovascular disease. The breadth and depth of his research contributions are truly extraordinary and place him among the elite pioneers in the fields of hypertension, vascular biology, and cardiovascular medicine. 
In 2011 Ernesto received the American Heart Association (AHA) Excellence in Research Award (formerly the Novartis Award), the highest honor of the AHA in the field of hypertension research. In 2018 he received the Distinguished Fellow Award of ISH and in 2013 he received the Robert Tigerstedt Distinguished Scientist Award of the American Society of Hypertension. Additional high honors from international organizations include the Irvine Page-Alva Bradley Lifetime Achievement Award of the Council for High Blood Pressure Research - AHA, the Björn Folkow Award of the European Society of Hypertension, the Margolese National Heart Disorders Prize from University of British Columbia, and the Queen Elizabeth II Diamond Jubilee Medal. Ernesto was elected Fellow of the Royal Society of Canada in 2006 and appointed Member of the Order of Canada (C.M.) in 2010.

Ernesto's service to scientific journals and professional societies has also been exemplary. He served as Associate Editor of Hypertension for more than 13 years and in 2016 was selected as editor-in-chief of the American Journal of Hypertension. He served as President of the ISH, President of the Inter-American Society of Hypertension, President of the Québec Hypertension Society, President of Hypertension Canada, Chair of the Council on Hypertension - AHA, and has held several other key leadership positions in scientific societies.

Ernesto has trained an impressive list of medical and graduate students as well as post-doctoral fellows, many of whom have assumed important faculty positions at academic institutions and leadership of international professional organizations. For example, Dr. Rhian Touyz, current Director of the Institute of Cardiovascular \& Medical Sciences at the BHF Glasgow Cardiovascular Research Centre at the University of Glasgow, United Kingdom and former President of the ISH, was one of Ernesto's protégés.

Ernesto is one of those rare clinician scientists who is innovative, scholarly, and a master of bridging basic and clinical research. His outstanding research contributions have had a major lasting impact on our understanding of the physiology, pathophysiology and therapy of hypertension and cardiovascular disease. We are delighted to congratulate Dr. Ernesto L. Schiffrin as the recipient of the 2021 Franz Volhard Award for Outstanding Research.

\section{References:}

1. Schiffrin EL, Park J-B, Intengan HD, Touyz RM. Correction of Arterial Structure and Endothelial Dysfunction in Human Essential Hypertension by the Angiotensin Receptor Antagonist Losartan. Circulation 2000;101:1653-1659. DOI: 10.1161/01. cir.101.14.1653

2. Amiri F, Virdis A, Neves MF, Iglarz M, Seidah NG, Touyz RM, Reudelhuber TL and Schiffrin EL. Endothelium-restricted overexpression of human endothelin-1 causes vascular remodeling and endothelial dysfunction. Circulation 2004;110:22332240 DOI: 10.1161/01.CIR.0000144462.08345.B9

3. De Ciuceis C, Amiri F, Brassard P, Endemann DH, Touyz RM, Schiffrin EL. Reduced vascular remodeling, endothelial dysfunction and oxidative stress in resistance arteries of angiotensin IIinfused macrophage colony-stimulating factordeficient mice: evidence for a role in inflammation in angiotensin-induced vascular injury. Arterioscl Thromb Vasc Biol 2005;25 2106-2113. DOl: 10.1161/01.ATV.0000181743.28028.57

4. Barhoumi T, Kasal DAB, Li MW, Shbat L, Laurant $P$, Fritsch Neves M, Paradis P, Schiffrin EL. T regulatory lymphocytes prevent angiotensin Il-induced hypertension and vascular injury. Hypertension. 2011;57:469-476. DOI: 10.1161/ HYPERTENSIONAHA.110.162941

5. Caillon A, Mian MOR, Fraulob-Aquino JC, Huo K-G, Barhoumi T, Ouerd S, Sinnaeve PR, Granger CB, Paradis P, Schiffrin EL. Gamma Delta T Cells Mediate Angiotensin II-Induced Hypertension and Vascular Injury. Circulation. 2017; 135:2155-2162 DOI: 10.1161/CIRCULATIONAHA.116.027058
John E. Hall - jehall@umc.edu

Robert M. Carey -RMC4C@hscmail.mcc.virginia.edu 